\title{
Study of ocean and wind energy potential with R: an innovative experience in the classroom
}

\author{
Ulazia, Alain ${ }^{\mathrm{a}}$ Ibarra-Berastegui, Gabriel ${ }^{\mathrm{a}}$
}

${ }^{\mathrm{a} D e p a r t m e n t}$ of NI and Fluid Mechanics, University of Basque Country, Spain.

\begin{abstract}
The Engineer School of Eibar initiated the Grade of Engineering in Renewable Energies four years ago. This pioneering educational project has shown many challenges to the teachers of the new grade. Among the different software skills used in this project, $R$ programming language has been a very important one because of its capacity for spatio-temporal analysis and graphical visualization of wind energy and wave energy potential. A quarter of the subject's program in Wind Energy and Ocean Energy has been used via Problem Based Learning for the application of statistical calculus with $R$. The aim of this contribution is to show some paradigmatic problems solved by the students and the results obtained. Finally, the opinion of the students about the use of $R$ and its learning potentiality have been gathered and analysed.
\end{abstract}

Keywords: R programming language; Renewable Energies; Wind Energy; Ocean Energy; Learning by Problems. 


\section{Introduction}

In this paper we briefly show the computational techniques used by the research group EOLO of the University of Basque Country because they have been applied in the teaching of the Wind Energy and Ocean Energy subjects. The interesting results of this didactic challenge are described here. Firstly, we will describe the research work and the pioneering grade in renewable energies, and after that, we will show some paradigmatic examples of problem solving by our students applying the mentioned research techniques. The results identify several $\mathrm{R}$ programming packages which establish structured methods for spatial and potential problem solving in the classroom. The final discussion underlines the satisfaction of our students and concludes with some reflections about problem solving and the heuristic of experts and novices. The research group EOLO has a long trajectory in mesoscale models in meteorology and in the prediction of wind and ocean waves (IbarraBerastegui et al., 2015a; Ibarra-Berastegui et al., 2015b). A challenging educational project, the new Grade of Engineering in Renewable Energies (Engineering School of Eibar, 2015) in the University of Basque Country, was a very good space to apply these computational techniques in an educational way. The new grade started four year ago with 70 students. After basic typical subject in engineering, the students specialized in the third and fourth year in several renewable technologies. Our contribution, from the area of Fluid Mechanics, was related to Wind Energy (third course) and Ocean Energy (fourth course). The teachers have obtained great results in the student's surveys and in the opinion of the teachers the students have executed a very active work based on self-learning and cooperative problem solving (Newell and Simon, 1972). This problem solving work has been done by $\mathrm{R}$ statistical programming language (R-cran, 2015), which offers a high variety of possibilities in different scientific areas; for us, mainly in the graphical visualizations and spatio-temporal analysis of datasets. In this way, the students have been able to visualize wind energy and wave energy potential spatially in geographical maps combining $\mathrm{R}$ with (Geographical Information System) GIS analysis thought other computational applications as Quantum GIS (2015). For that, data from different mesoscale models (Weather Research and Forecasting, WRF) and remote sensing data (CCMP -Cross Calibrated Multi Platform-, QuikSat, RSS DISCOVER -Remote Sensing Data Discover-, TOPEX, ETOPO1) has been used, with refined datasets offered by satellites which are combined and improved via cross calibrated multi-platform systems. In this way, the students can obtain wind speed and direction at $10 \mathrm{~m}$, isolines of the ocean bathymetry, wave height and period, or the direction of wave flux. Besides that, the students even have been able to compare satellite and mesoscale model data against observed data. In the case of ocean energy final grade pojects, several observations of sea buoys of the Spanish State Port Authority have been used for that purpose. 


\section{Learning by Problems}

All this activity offers a real and pragmatic way of problem solving to our students, simulating what the scientist do every day and using the logic of discovery instead of the logic of justification (Hanson, 1958). As Clement says (Clement, 1988, 2008) in his deep study of scientific creativity that deals with a problem, there is no difference heuristically between the problem solving capacity of an expert and of a student. That is, the students should know the real scientific practice, and not only the final important and supposedly finished theories (Chi et al. 1981, 1989). The state of the art in this domain has been developed very quickly mainly in constructive problem solving via the use of analogy and different heuristic roles has been pointed out for that. The methodological analogy is an important one and this is our $\mathrm{R}$ programming purpose in the classroom for two subjects: Wind Energy and Ocean Energy. Only paradigmatic examples of the student's work are presented here, which together with the other raised problems design a suitable environment for constructive learning (Simons, 1993; Welsh, 2012) based on the versatility of the $\mathrm{R}$ programming language.

\subsection{Wind Energy}

In the subject of Wind Energy 23 teams of three students has elaborated the statistics of wind resource and the estimation of annual energy production for different turbine types. For that, Weibull distribution's $k$ and $c$ parameters have been obtained to fit the histogram of wind speed (see Figure 1). For example, for that purpose, MASS and ismev statistical packages have been used (see section 3. Results) by means of fit.distr function. Therefore, the Weibull fitting calculates the necessary wind parameters $(k$ and $c)$ to estimate the annual wind energy production of any turbine if we have its power curve.

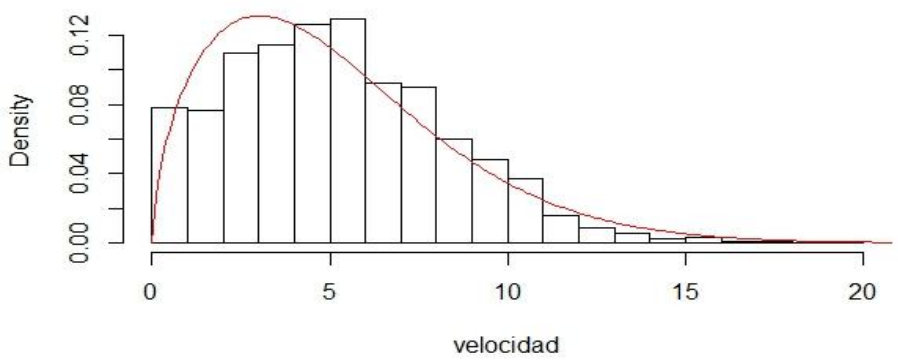

Figure 1. Histogram of velocities and Weibull fitting.

Besides that, wind rose has been plotted using the direction data vector to interpret the qualitative wind characteristics of the considered location (Figure 2). Two packages can be used for that: openair or circular. The wind rose of the figure fits the Von Mises 
Distribution with different smoothness in red, green and blue colour, which is a specific distribution for wind direction that can be represented in polar coordinates. In this way, the main wind direction is visually expressed for different smoothness capacity. The fitting visualizes clearly that the main wind direction is the Northwest in the considered location.



Figure 2. Wind Rose with three fitting resolutions.

\subsection{Ocean Energy}

12 problems about the estimation of ocean wave energy with a duration of a week (4 class hours) has been developed during the subject by two groups of 20 students. Wave energy flux and the spatial distribution of technologies that could capture this energy depends strongly on the depth of the ocean floor or its bathymetry. The data of the project ETOPO1 (2015), the newest generation of topographic and bathymetric global measures by NOOA, are directly linked with $\mathrm{R}$ by means of marmap package that can be immediately and freely installed by the students. Figure 3 shows one of the maps obtained by one of the students for the Gulf of Biscay. The possibility to draw isolines (isobaths in this case) and obtain colored maps in one of the great potentials of $\mathrm{R}$ in mapping spacial parameters. 


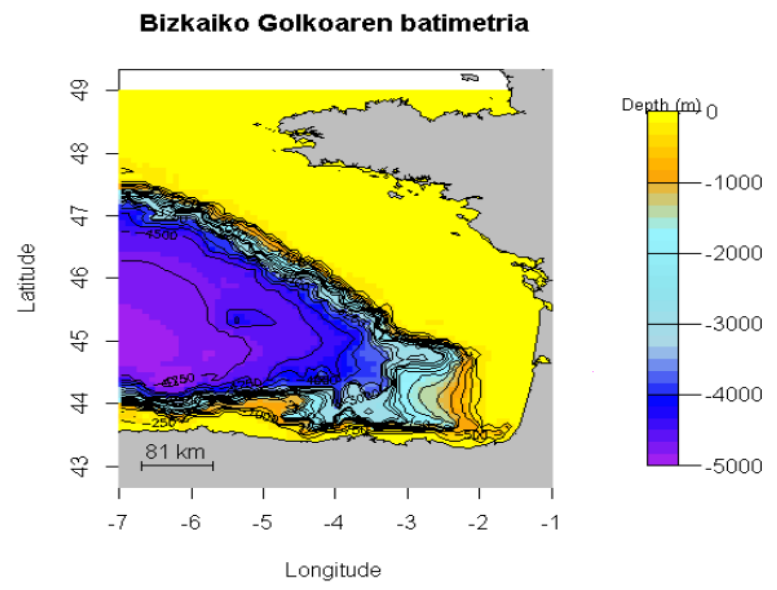

Figure 3. Bathymetry of the Gulf of Biscay.

The following image (Figure 4) shows another coloured map, but in this case the wave energy potential is mapped in the Gulf of Biscay. TOPEX satellite data have been employed for that, calculating the mean wave height and period in its gridpoint where the satellite measures the surface of the sea. Since the wave energy potential is proportional to the period and to the square of the wave height, wave energy potential can be calculated in each gridpoint. After that, $\mathrm{R}$ is able to create a gradual coloured map over the original satellite resolution and to reference it by means of a colour palette (in the right). 




Figure 4. Wave Energy in the Gulf of Biscay.

Similarly, the students have obtained a global map of wave energy distribution (see Figure 5). Besides that, they have represented the maximum (green) and minimum (red) wave energy potential positions in the world, after developing a elaborated calculus with the dataframes offered by TOPEX. In this way, the treatment and transformation of different formats of datasets and geographical reference systems are also practical issues that our students have learned. 




Figure 5. Global wave energy distribution.

\section{Results}

Several statistical methods for the estimation and analysis of wind and wave energy potential has been treated in our course. We want to emphasize the following practical skills that simulates everyday scientific activity developed by our students in the use of $\mathrm{R}$ and the constructive and potentially creative character of them:

- the $s p$ package to import, export and manipulate geographical data that are structured by raster models (Bivand, 2011).

- The packages maps and mapdata which offer shorelines, rivers and political boundaries in low resolution (Becker eta al, 1995).

- The marmap package to study bathymetry and isolines on the ocean floor (Pante 2015).

- Ismev and evir packages to fit Gumbel's GEV model to the statistics of extreme events as huge waves on the coast (Gilleland 2012).

- The package RNetCDF (Network Common Data Form) to read and manipulate the common.$n c$ dataset format in climatology, oceanography and meteorology.

Furthermore, surveys point to considerable success in the classroom. The general opinion about the two subjects and the use of $\mathrm{R}$ has been between 4.3 and 4.5 out of 5 . The students 
valued very positively the use of advanced software, and cooperative and practical know how in the estimation of offshore wind and ocean wave energy potential.

\section{Discussion and Future Outlook}

Compared with other similar subjects students' opinion establishes a hight mark, since many of them present general opinion below 4 or even 3 out of 5 . We do not have data about the students' opinion for the same subject with other teaching methods because it is a new grade. But the mean opinion for all the University of Basque Country is 3.5, and this reference tells us that the opinion of our students is really good, better if we take into account that it is a totally new subject in our university. In fact, our teaching method weakens the rigidity of justification context in favour of discovery. This tendency is so important that the students design their own open problems as they are working with $\mathrm{R}$. According to our experience, 15 hours are enough to develop the needed programming base for a creative disposition in the classroom. This new ideas suppose a constructive approach in a cooperative way, since the students work together helping each other in every moment. What is more, some final grade projects has been developed starting from the ideas surged in this didactic environment. We think that this educational challenge which binds programming and an open, innovative and exciting area as Ocean Energy offers a powerful example on problem based learning, not only for its capacity to solve many different problems, but because of its capacity to generate open problems in a constructive way. This constructive aspect creates a rich learning environment via cooperation. The teacher lecture work ends in the first third of the subject program and the following time can be used to solve several problems and to raise new ones. The idea is to learn while doing. Furthermore, this activity constitutes a fruitful heuristic work for students that is adaptable to any other environment. Briefly speaking and remembering Clement's work, if we take into account that there is no difference between the problem solving capacity of an expert and of a student, we simulate directly expert's know how in the classroom. In our opinion, this methodological focus is what encourages the motivation of our students and their creative confidence, which offers many educational variables for future planning based on problem solving and simulation of what experts do.

\section{References}

Clement, J. (1988). Observed methods for generating analogies in scientific problem solving. Cognitive Science, 12(4), 563-586.

Clement, J. (2008). Creative model construction in scientists and students: The role of imagery, analogy, and mental simulation. Springer Science \& Business Media. 
Chi, M. T., Feltovich, P. J., \& Glaser, R. (1981). Categorization and representation of physics problems by experts and novices. Cognitive science, 5(2), 121-152.

Chi, M. T., Bassok, M., Lewis, M. W., Reimann, P., \& Glaser, R. (1989). Selfexplanations: How students study and use examples in learning to solve problems. Cognitive science, 13(2), 145-182.

Bivand. R. (2011). http://rspatial.r-forge.r-project.org/

Becker, R.A., eta A. R. Wilks (1995). Constructing a Geographical Database. AT\&T Bell Laboratories Statistics Research Report [95.2].

Engineering School of Eibar (2015-11-30). URL: http://www.ehu.eus/eu/web/eibar

ETOPO1 (2015-11-30). URL: https://www.ngdc.noaa.gov/mgg/global/global.html

Gilleland, E. (2012). https://www.ral.ucar.edu/ ericg/softextreme.php

Hanson, N. R. (1958). The logic of discovery. The Journal of Philosophy, 1073-1089.

Ibarra-Berastegi, G., Saenz, J., Esnaola, G., Ezcurra, A., \& Ulazia, A. (2015a). Short-term forecasting of the wave energy flux: Analogues, random forests, and physics-based models. Ocean Engineering, 104, 530-539.

Ibarra-Berastegi, G., Saenz, J., Esnaola, G., Ezcurra, A., \& Ulazia, A. (2015b, May). Shortterm forecasting of zonal and meridional wave energy flux in the Bay of Biscay using random forests. In OCEANS 2015-Genova (pp. 1-6). IEEE.

Newell, A., \& Simon, H. A. (1972). Human problem solving (Vol. 104, No. 9). Englewood Cliffs, NJ: Prentice-Hall.

Pante, E. 2015. http://www.ngdc.noaa.gov/mgg/geodas/geodas.html

QGIS (2015-11-30). URL: http://www.qgis.org/en/site/

R-CRAN (2015-11-30). URL: https://cran.r-project.org/

Simons, P. R. J. (1993). Constructive learning: The role of the learner. In Designing environments for constructive learning (pp. 291-313). Springer Berlin Heidelberg.

Welsh, T. M. (2012). Designing environments for constructive learning (Vol. 105). T. M. Duffy, J. Lowyck, \& D. H. Jonassen (Eds.). Springer Science \& Business Media. 